\title{
Produtividade do minimilho em função das adubações nitrogenada e potássica ${ }^{1}$
}

\author{
Renato Frederico dos Santos 2 , Tadeu Takeyoshi Inoue ${ }^{3}$, Carlos Alberto Scapim 4 , Luiz Rafael Clovis ${ }^{5}$, \\ Lia Mara Moterle ${ }^{6}$ Fernando César Sales Saraiva
}

\begin{abstract}
RESUMO
Há grande carência de informações quanto à adubação com Nitrogênio e Potássio para a produção de minimilho. Quando colhido antes do início da formação de grãos, as quantidades de nutrientes exigidas podem ser diferenciadas. Por essa razão, o presente trabalho teve por objetivo avaliar a resposta do minimilho às adubações nitrogenada e potássica em solo de textura média na região de Maringá, gerando dados que possibilitam a recomendação da aplicação de doses adequadas desses nutrientes para a cultura, evitando os desperdícios e a contaminação ambiental. Os experimentos foram conduzidos na Fazenda Experimental de Iguatemi, na safra verão 2010/2011 e safrinha 2011. O delineamento experimental para os dois experimentos foi blocos casualizados no esquema fatorial $4 \mathrm{x} 4$, utilizando-se quatro doses de nitrogênio (N) $\left(0,50,75\right.$ e $\left.100 \mathrm{~kg} \mathrm{ha}^{-1}\right)$ e quatro de potássio $(\mathrm{K})\left(0,20,40 \mathrm{e} 60 \mathrm{~kg} \mathrm{ha}^{-1}\right)$, aplicadas $50 \%$ na semeadura e 50\% em cobertura no estádio V6 de desenvolvimento. O cultivar de milho-pipoca utilizado foi o IAC 125, híbrido triplo top cross, de ciclo precoce. Para as condições em que foi realizada a pesquisa, o potássio e a interação NK não influenciaram a altura de plantas e o comprimento das espiguetas comerciais na safra verão. A máxima produtividade de minimilho, na safra verão, foi obtida com a aplicação de $64,35 \mathrm{~kg} \mathrm{ha}^{-1}$ de nitrogênio, não havendo incremento na produtividade com a aplicação de potássio. Na safrinha, a maior produtividade foi alcançada com a combinação das doses 60,9 e $51,23 \mathrm{~kg} \mathrm{ha}^{-1}$ de nitrogênio e potássio, respectivamente.
\end{abstract}

Palavras-chave: Zea mays L., adubação, componentes de rendimento.

\section{ABSTRACT}

\section{Effect of nitrogen and potassium fertilization on baby corn yield}

There is a lack of information regarding nitrogen and potassium fertilization on the production of baby corn. When ears are collected before grain formation, the amounts of required nutrients can be differentiated. This study evaluated the response of baby corn at different nitrogen and potassium fertilization rates in a medium texture soil in the region of Maringá PR Brazil. Data for adequate nutrient recommendation are produced for the crop, avoiding losses and environmental contamination. The experiment was conducted in the Iguatemi Experimental Farm during the summer harvest of 2010-2011 and the second corn crop of 2011. The experiment was arranged in a $4 \mathrm{x} 4$ factorial randomized block design with a, with 4 rates of nitrogen $\left(0,50,75\right.$ and $\left.100 \mathrm{~kg} \mathrm{ha}^{-1}\right)$ and 4 rates of potassium $(0,20,40$ and $60 \mathrm{~kg} \mathrm{ha}$

Recebido para publicação em 02/10/2012 e aprovado em 08/08/2013.

'Parte da tese de doutorado do primeiro autor.

${ }^{2}$ Engenheiro-Agrônomo, Mestre. Departamento de Agronomia, Universidade Estadual de Maringá, Avenida Colombo, 5790, 87020-900, Maringá, Paraná, Brasil. agronomorenato@hotmail.com

${ }^{3}$ Engenheiro-Agrônomo, Doutor. Departamento de Agronomia, Universidade Estadual de Maringá, Avenida Colombo, 5790, 87020-900, Maringá, Paraná, Brasil. ttinoue@ uem.br ${ }^{4}$ Engenheiro-Agrônomo, Doutor. Departamento de Agronomia, Universidade Estadual de Maringá, Avenida Colombo, 5790, 87020-900, Maringá, Paraná, Brasil. cascapim@ uem.b ${ }^{5}$ Engenheiro-Agrônomo, Mestre. Departamento de Agronomia, Universidade Estadual de Maringá, Avenida Colombo, 5790, 87020-900, Maringá, Paraná, Brasil. luizrafaelclovis@ hotmail.com (autor correspondente).

${ }^{6}$ Engenheira-Agrônoma, Doutora. Departamento de Agronomia, Faculdade Integrado de Campo Mourão, Rodovia BR 158, Km 207, 87300-970, Campo Mourão, Paraná, Brasil. Imoterle@ hotmail.com

${ }^{7}$ Engenheiro-Agrônomo. Departamento de Agronomia, Universidade Estadual de Maringá, Avenida Colombo, 5790, 87020-900, Maringá, Paraná, Brasil. fernando_cssa @ hotmail.com 
${ }^{1}$ ), with 50\% applied at seeding and 50\% topdressed at the V6 development stage. The popcorn triple hybrid cultivar IAC 125 was used in the experiment. The results showed that potassium and the interaction NK did not influence plant height and length of commercial ears. Maximum babycorn yield was achieved with $64.35 \mathrm{~kg} \mathrm{ha}^{-1}$ of nitrogen. The combination of the rates 60.9 of nitrogen and $51.23 \mathrm{~kg} \mathrm{ha}^{-1}$ of potassiumprovided the highest yield in the second corn crop of baby corn.

Key words: Zea mays L., fertilization, yield components.

\section{INTRODUÇÃO}

O milho (Zea mays L.) é cultivado em todo território brasileiro, destacando-se das demais culturas por ocupar a maior extensão em área cultivada no País. É utilizado na alimentação humana em diversas formas de grãos secos, verdes, in natura, em preparados ou como minimilho. $\mathrm{O}$ último, também conhecido como "baby corn", corresponde à inflorescência feminina da planta de milho, popularmente denominada "boneca", que apresenta os estilos estigmas com até $3 \mathrm{~cm}$, colhida antes da fertilização (Pereira Filho et al., 1998). Pode ser consumido in natura, como produtos processados pela indústria alimentícia na forma de conservas acidificadas, e como picles caseiros.

Um dos fatores que leva à maior rentabilidade da exploração comercial da cultura é seu menor custo de produção pela sua colheita precoce, quando comparada à lavoura de milho para produção de grãos, pois o gasto com defensivos agrícolas para o controle de danos causados por insetos e doenças é menor. Além disso, o ciclo do milho comum chega até 140 dias, enquanto o minimilho é colhido entre 60 e 75 dias, o que permite até cinco safras anuais na mesma área de cultivo (Queiroz, 2008). Nas regiões tropicais, pode ser cultivado o ano todo, desde que haja irrigação no período de deficiência hídrica; entretanto, nas regiões mais frias, no período de pleno inverno, a produção pode cair muito e o ciclo se prolongar demais (Pereira Filho \& Cruz, 2001). Dessa maneira, destaca-se como atividade economicamente viável para pequenas propriedades (Queiroz, 2008).

O minimilho pode ser produzido a partir do milho comum, doce ou pipoca (Pereira Filho \& Cruz, 2001). Para a produção de grande número de espiguetas por área cultivada, os genótipos utilizados para a atividade devem ser prolíficos e semeados com densidade populacional três vezes maior quando comparado ao milho comum, utilizando-se até 15 sementes por metro linear. Apesar da maior densidade populacional da cultura do minimilho, a adubação é realizada seguindo as recomendações para o milho comum (Coelho, 2006; Fancelli \& Dourado-Neto, 2007). Normalmente são aplicados entre 100 e $150 \mathrm{~kg} \mathrm{ha}^{-1}$ de $\mathrm{N}$ e 50 e $100 \mathrm{~kg} \mathrm{ha}^{-1}$ de $\mathrm{K}_{2} \mathrm{O}$, divididos entre semeadura e cobertura.
O conhecimento das exigências nutricionais e da absorção de nutrientes pela planta é um fator importante para auxiliar no manejo da adubação. O milho pode apresentar um ou mais picos de absorção com relação aos diferentes nutrientes. A exigência de $\mathrm{N}$ pela cultura do milho é em consequência da sua função estrutural, pois ele faz parte de moléculas de compostos orgânicos, como os aminoácidos e as proteínas (Malavolta, 2006). A planta também depende do $\mathrm{N}$ para a realização de processos vitais, como síntese de proteína, absorção iônica, fotossíntese, respiração, multiplicação e diferenciação celular (Marschner, 1995; Malavolta, 2006), proporcionando vegetação verde e abundante, aumento na folhagem e nos teores de proteínas, rápido crescimento e auxílio aos microrganismos do solo para a decomposição da matéria orgânica.

Depois do nitrogênio, o potássio é o elemento absorvido em maior quantidade pelo milho, sendo em média, $20 \%$ exportado nos grãos. Esse elemento está relacionado com a produção de fito-hormônios que estão envolvidos no crescimento de tecidos meristemáticos na planta. Além disso, ele é de fundamental importância na fotossíntese, entendida como a transformação da energia luminosa em energia química (ATP e NADHP). Como todas as funções vitais da planta dependem, direta ou indiretamente, de ATP e NADHP, o efeito direto do Potássio refletirá, segundo Epstein (1975), em maior assimilação de $\mathrm{CO}$; maior translocação de carboidratos produzidos nas folhas para os outros órgãos da planta; no uso eficiente da água, devido ao maior controle na abertura e no fechamento dos estômatos; em maior eficiência enzimática, por atuar como ativador em reações enzimáticas; e por permitir maior suprimento de proteínas, componentes essenciais das enzimas.

Como o minimilho é colhido antes do início da formação de grãos, tanto as quantidades de nutrientes quanto o parcelamento desses podem ser diferenciados, devendo ser realizados experimentos para verificação das quantidades ideais a serem fornecidas.

Dessa forma, o objetivo deste trabalho foi avaliar o efeito da aplicação de diferentes doses de nitrogênio e potássio sobre as características biométricas e produtividade de espiguetas na cultura minimilho, em Maringá-PR. 


\section{MATERIAL E MÉTODOS}

Os experimentos foram conduzidos na Fazenda Experimental de Iguatemi - FEI, no município de Maringá, região Noroeste do Paraná, com coordenadas geográficas latitude $23^{\circ} 11^{\prime} \mathrm{S}$, longitude $52^{\circ} 03^{\prime} \mathrm{W}$ e altitude 550 m. O clima da região é do tipo Cfa, de acordo com a classificação de Köppen. O solo da área experimental é classificado como um Latossolo Vermelho distroférrico (Embrapa, 1999). Os resultados da análise química do solo, realizada antes da instalação dos experimentos, encontram-se na Tabela 1.

O cultivar de milho-pipoca utilizado foi o IAC 125, híbrido triplo top cross, de ciclo precoce. O trabalho foi conduzido na safra verão 2010/2011 e na safrinha 2011, sendo instalado nos dias 27/10/2010 e 25/02/2011, respectivamente. Os experimentos foram conduzidos em área sob irrigação por aspersão e sistema de plantio convencional.

O delineamento experimental foi de blocos completos com tratamentos aleatorizados no esquema fatorial $4 \times 4$, sendo quatro doses de nitrogênio (fonte Ureia) $(0,50,75$ e $100 \mathrm{~kg} \mathrm{ha}^{-1}$ ) e quatro de potássio (fonte Cloreto de Potássio) (0, 20, 40 e $\left.60 \mathrm{~kg} \mathrm{ha}^{-1}\right)$, aplicando-se 50\% na semeadura e $50 \%$ em cobertura no estádio V6 de desenvolvimento.

A adubação fosfatada foi realizada conforme recomendação descrita por Coelho (2006). As parcelas experimentais foram compostas por seis linhas espaçadas $0,9 \mathrm{~m}$ entre si e 5,0 m de comprimento, totalizando $27 \mathrm{~m}^{2}$. Na coleta dos dados foram descartadas as duas linhas laterais e 1,0 $\mathrm{m}$ de cada lado no sentido do seu comprimento, totalizando $10,8 \mathrm{~m}^{2}$ de área útil.

A semeadura foi realizada manualmente em uma densidade de 15 plantas $\mathrm{m}^{-1}$, totalizando $187.500 \mathrm{pl} \mathrm{ha}^{-1}$. Os produtos utilizados durante os tratos culturais foram Match (Syngenta), Lannate (DuPont), Lorsban 480 BR (Dow AgroScience), Copstar (Bayer CropScience), Trop (Milenia) e Opera (Basf). As doses procederam-se segundo as recomendações técnicas presentes na bula de cada produto.
As colheitas foram realizadas nas primeiras horas do dia, para evitar possível perda de umidade das espiguetas. A primeira foi feita três dias após o aparecimento dos pendões. O florescimento iniciou-se aos 57 dias após a semeadura. Em ambos os experimentos foram realizadas 10 colheitas com intervalos de dois dias. Após colhidas, as espiguetas foram colocadas em sacos plásticos, acondicionados em caixas de isopor e, posteriormente, levadas para o Laboratório de Tecnologia de Produtos de Origem Vegetal - UEM, onde foram aferidos o comprimento e a massa das espiguetas. As variáveis agronômicas e comerciais avaliadas foram:

- Altura de plantas: verificada por ocasião do pleno florescimento, mensurada por meio do comprimento do colmo (da superfície do solo até a base da inflorescência masculina - "pendão"), mediante o uso de fita graduada (trena), sendo consideradas seis plantas por parcela.

- Diâmetro do colmo: determinado na parte mediana do segundo internódio, a partir da base de seis plantas, o qual foi mensurado por meio do uso de um paquímetro. A determinação foi efetuada por ocasião do pleno florescimento.

- Número de espiguetas comerciais: obtido pela contagem de todas as espiguetas desempalhadas que apresentaram diâmetro variando entre 0,8 e 1,8 cm e comprimento entre 4 a $12 \mathrm{~cm}$, cor variando de branco-pérola a creme-claro, formato cilíndrico e espiguetas não fertilizadas na área útil da parcela.

- Comprimento da espigueta: comprimento médio de 10 espiguetas por parcela, medido em centímetros, com o auxílio de uma régua graduada.

- Massa de espiguetas comerciais: obtida pela pesagem em balança digital semianalítica de todas as espiguetas comercias que apresentavam diâmetro variando entre 0,8 e $1,8 \mathrm{~cm}$ e comprimento entre 4 e $12 \mathrm{~cm}$, formato cilíndrico e espiguetas não-fertilizadas na área útil da parcela. Todas as espiguetas colhidas nas áreas úteis fo-

Tabela 1. Resultados da análise química da camada de 0 - $15 \mathrm{~cm}$ do solo Argissolo Vermelho distroférrico, antes da implantação da cultura

\begin{tabular}{|c|c|c|c|c|c|c|c|c|c|c|c|c|}
\hline \multicolumn{13}{|c|}{ Safra verão 2010/2011 } \\
\hline \multirow{2}{*}{$\begin{array}{l}\text { Prof. } \\
(\mathrm{cm})\end{array}$} & \multirow{2}{*}{$\begin{array}{c}P^{(1)} \\
\mathrm{mg} \mathrm{dm}^{-3}\end{array}$} & \multicolumn{2}{|c|}{$\mathrm{pH}^{(2)}$} & $\mathbf{H}^{+}+\mathrm{Al}^{3+}$ & $\mathbf{A l}^{3+}$ & $\mathbf{K}^{+(\mathbf{1})}$ & $\mathbf{C a}^{+2}$ & $\mathbf{M g}^{2+(3)}$ & SB & CTC & $\mathbf{V}$ & $\mathbf{C}^{(4)}$ \\
\hline & & $\mathrm{CaCl}_{2}$ & $\mathrm{H}_{2} \mathrm{O}$ & \multicolumn{7}{|c|}{$\mathrm{cmol}_{\mathrm{c}} \mathbf{d m}^{-3}$} & $\%$ & $\mathrm{~g} \mathrm{dm}^{-3}$ \\
\hline $0-15$ & 8,12 & 5,3 & 5,8 & 3,55 & 0 & 0,46 & 5,74 & 1,06 & 7,26 & 10,81 & 67,16 & 15,22 \\
\hline \multicolumn{13}{|c|}{ Safrinha 2011} \\
\hline Prof. & $\mathbf{P}^{(1)}$ & \multicolumn{2}{|c|}{$\mathbf{p H}^{(2)}$} & $\mathbf{H}^{+}+\mathrm{Al}^{3+}$ & $\mathbf{A l}^{3+}$ & $\mathbf{K}^{+(1)}$ & $\mathbf{C a}^{+2}$ & $\mathbf{M g}^{2+(3)}$ & SB & CTC & $\mathbf{V}$ & $\mathbf{C}^{(4)}$ \\
\hline$(\mathbf{c m})$ & $\mathbf{m g ~ d m}{ }^{-3}$ & $\mathrm{CaCl}_{2}$ & $\mathrm{H}_{2} \mathrm{O}$ & \multicolumn{7}{|c|}{$\mathrm{cmol}_{\mathrm{c}} \mathbf{d m}^{-3}$} & $\%$ & $\mathrm{~g} \mathrm{dm}^{-3}$ \\
\hline $0-15$ & 22,05 & 4,90 & 5,3 & 4,12 & 0,10 & 0,22 & 3,54 & 0,89 & 4,66 & 8,78 & 53,06 & 14,39 \\
\hline
\end{tabular}

Prof.: Profundidade. ${ }^{(1)}$ Extrator Mehlich 1; ${ }^{(2)} \mathrm{CaCl}_{2} 0,01 \mathrm{~mol} \mathrm{~L}^{-1} ;{ }^{(3)} \mathrm{KCl} 1 \mathrm{~mol} \mathrm{~L}^{-1}$; e ${ }^{(4)}$ Método Walkley-Black. 
ram pesadas sem palha. Os dados de peso de espiguetas comerciais foram transformados para $\mathrm{kg} \mathrm{ha}^{-1}$.

Realizou-se a análise de variância para as combinações de doses de nitrogênio e de potássio. Posteriormente, houve a seleção de variáveis regressoras para compor os modelos para cada variável. O modelo de regressão múltipla inicialmente avaliado foi:

$Y i=\beta 0+\beta 1 i N i+\beta 2 i K i+\beta 3 i N i^{2}+\beta 4 i K i^{2}+\beta 5 i N K+\varepsilon i$

A técnica de regressão empregada foi o método "Backward", o qual incorpora inicialmente todas as variáveis e depois, por etapas, cada uma pode ser ou não eliminada. A decisão de retirada da variável é tomada baseando-se em testes $F$ parciais, que são calculados para cada variável como se ela fosse a última a entrar no modelo. Para cada variável explicativa calcula-se a estatística F. O menor valor das estatísticas F parciais calculadas é então comparado com o F crítico, Fsaída, calculado para dado valor $\alpha$ crítico. Se o menor valor encontrado for menor do que Fsaída, elimina-se do modelo a covariável responsável pelo menor valor da estatística $\mathrm{F}$ parcial e ajusta-se novamente o modelo. As estatísticas F parciais são calculadas para esse modelo e o processo é repetido. $\mathrm{O}$ algoritmo de eliminação termina quando a menor estatística F parcial não for menor do que Fsaída.

A significância do teste $F$ para essas combinações foi avaliada por regressão pelo comando RSREG do programa estatístico "Statistical Analysis System" (SAS Institute, 2000). Nas variáveis diâmetro do colmo e número de espiguetas comerciais, na safrinha, em que os pontos críticos foram de sela, optou-se pelo corte na superfície de resposta, o que permitiu o ajuste de curvas de regressões polinomiais. Adotou-se nível de significância de $5 \%$ em todas as análises estatísticas.

\section{RESULTADOS E DISCUSSÃO}

$\mathrm{Na}$ Tabela 2, veem-se efeitos significativos para $\mathrm{N}$ tanto na safra de verão como na safrinha, mas não houve efeito significativo $(\mathrm{P}>0,05)$ de $\mathrm{K}, \mathrm{K}^{2}$ e NK para o diâmetro do colmo de plantas. Contudo, esse diâmetro variou em razão do fornecimento de nitrogênio, segundo modelo linear de regressão (Figura 1A).

Observa-se nos resultados da Figura 1A que para cada unidade de variação na dose de nitrogênio, ou seja, para cada $1,0 \mathrm{~kg} \mathrm{~N}^{-1}$ que se aumenta na dose de $\mathrm{N}$ ocorre aumento de $0,04247 \mathrm{~mm}$ (coeficiente angular) no diâmetro do colmo das plantas de minimilho. Da mesma forma, porém estudando doses de nitrogênio no milho safrinha em sucessão à cultura da soja, Soratto et al. (2010) observaram que o diâmetro do colmo foi incrementado pela elevação das doses de nitrogênio em cobertura, independentemente da fonte utilizada.
Esses resultados discordam dos encontrados por Pereira Filho et al. (2005), os quais não observaram diferenças significativas no diâmetro do colmo com o aumento de doses de nitrogênio. Entretanto, o incremento nessa variável verificado no presente estudo é satisfatório, uma vez que maiores diâmetros permitem plantas menos suscetíveis ao acamamento ou quebramento, bem como à ocorrência de doenças, especialmente as podridões de colmo (Pereira Filho \& Cruz, 2000), fatos esses observados na produção de minimilho, na qual se utilizam altas densidades de plantas (Almeida et al., 2005).

Segundo Bull (1993), plantas adequadamente nutridas com nitrogênio têm maior desenvolvimento vegetativo, uma vez que o nutriente influencia diretamente a divisão e expansão celular e o processo fotossintético. Esse elemento apresenta influência na constituição dos componentes morfológicos e na formação do colmo, que servirá de órgão de armazenamento de sólidos solúveis ou fotoassimilados, os quais posteriormente serão translocados e utilizados no processo de granação; ou seja, formação dos grãos.

Desse modo, pode-se afirmar que o aumento do diâmetro do colmo se traduz, além de suporte à planta, em produtividade (Ritchie et al. 2003; Souza \& Soratto, 2006; Soratto et al., 2010).

Em relação à variável diâmetro do colmo, no cultivo da safrinha não foi possível encontrar o ponto crítico. Dessa forma, foram feitos cortes na superfície, o que possibilitou o ajuste de regressões polinomiais (Figuras 1B e 1C). Assim, foi possível estimar a resposta máxima de diâmetro de 13,19 mm, 13,36 mm, 13,72 mm e 14,26 mm (máximos das funções), quando utilizadas as doses de 0, 20, 40 e 60 $\mathrm{kg} \mathrm{ha}^{-1}$ de potássio, respectivamente, a qual pode ser alcançada pela aplicação da dose de $74,12 \mathrm{~kg} \mathrm{ha}^{-1}$ (ponto de máximo) de nitrogênio (Figura 1B).

Em contrapartida, o desdobramento de diferentes doses de potássio em cada dose de nitrogênio, a partir de cortes na superfície, permitiu o ajuste de regressões polinomiais, as quais possibilitaram o cálculo do ponto de mínimo (Figura 1C).

Segundo Luecking et al. (1983) e Mackenzie et al. (1988), altas doses de potássio, combinadas com altas doses de nitrogênio, interagem para aumentar a produção de grãos e massa seca em plantas de milho. Para esses autores, apesar do potássio não participar de compostos estruturais nas plantas, esse nutriente desempenha importante papel em vários processos bioquímicos e fisiológicos dos vegetais. O potássio também influencia a utilização de nitrogênio pelas culturas. Segundo Xu et al. (1992), o crescimento de plântulas de milho com $\mathrm{NH}_{4}^{+}$foi mais vigoroso quando houve suplementação com potássio. Esse processo também pôde ser observado neste estudo com o fornecimento das maio- 
res doses de potássio associado ao nitrogênio, determinando maior diâmetro do colmo.

A altura de planta considerada ótima para facilitar a colheita de minimilho varia entre 1,9 e 2,5 m (Rodrigues et al., 2004; Embrapa, 2010). Na cultura do minimilho, a maior altura de plantas aliada à utilização de altas densidades é considerada fator negativo sobre a produtividade, pois favorece o acamamento das plantas. Por outro lado, está

Tabela 2. Quadrado médio para os dados de diâmetro do colmo (DC), altura de plantas (AP), comprimento das espiguetas comerciais (COMP), produtividade (PROD) e número de espiguetas comerciais (NESP) em razão de doses de nitrogênio e potássio, safra verão e safrinha

\begin{tabular}{|c|c|c|c|c|c|c|}
\hline \multicolumn{7}{|c|}{ Safra Verão } \\
\hline Fontes de variação & GL & DC (mm) & $\mathbf{A P}(\mathbf{m})$ & $\operatorname{COMP}(\mathrm{mm})$ & PROD $\left(\mathrm{kg} \mathrm{ha}^{-1}\right)$ & NESP \\
\hline Nitrogênio (N) & 3 & $84,080 *$ & $0,718^{*}$ & $0,943^{*}$ & $265729,581^{*}$ & $3581,779 *$ \\
\hline Potássio (K) & 3 & $6,968^{\mathrm{ns}}$ & $0,017^{\mathrm{ns}}$ & $0,052^{\mathrm{ns}}$ & $37209,301^{\mathrm{ns}}$ & $1067,613^{\mathrm{ns}}$ \\
\hline $\mathrm{N} \times \mathrm{K}$ & 9 & $3,697^{\mathrm{ns}}$ & $0,008^{\mathrm{ns}}$ & $0,398^{\mathrm{ns}}$ & $49866,422 *$ & $1183,146^{*}$ \\
\hline Blocos & 4 & $14,525^{*}$ & $0,041^{*}$ & $0,512^{\mathrm{ns}}$ & $11857,105^{\mathrm{ns}}$ & $528,738^{\text {ns }}$ \\
\hline Resíduo & 60 & 4,525 & 0,011 & 0,278 & 17267,810 & 462,591 \\
\hline Média geral & - & 14,931 & 2,172 & 9,291 & 930,506 & 146,163 \\
\hline $\mathrm{CV}(\%)$ & - & 14,25 & 4,85 & 5,68 & 14,12 & 14,72 \\
\hline \multicolumn{7}{|c|}{ Safrinha } \\
\hline Fontes de variação & GL & DC (mm) & $\mathbf{A P}(\mathbf{m})$ & COMP (mm) & PROD $\left(\mathrm{kg} \mathrm{ha}^{-1}\right)$ & NESP \\
\hline Nitrogênio (N) & 3 & $14,541 *$ & $0,252 *$ & $1,809 *$ & $506787,263 *$ & $12609,146^{*}$ \\
\hline Potássio (K) & 3 & $1,628^{\mathrm{ns}}$ & $0,010^{\mathrm{ns}}$ & $0,570^{\mathrm{ns}}$ & $63658,082 *$ & $1607,513 *$ \\
\hline $\mathrm{N} \times \mathrm{K}$ & 9 & $1,060^{\mathrm{ns}}$ & $0,007^{\mathrm{ns}}$ & $0,309^{\text {ns }}$ & $16185,679^{\mathrm{ns}}$ & $1019,001 *$ \\
\hline Blocos & 4 & $9,222 *$ & $0,061 *$ & $0,409^{\text {ns }}$ & $3962,191^{\mathrm{ns}}$ & $1079,581 *$ \\
\hline Resíduo & 60 & 1,144 & 0,005 & 0,233 & 9149,514 & 413,401 \\
\hline Média geral & - & 13,184 & 1,565 & 8,300 & 806,277 & 173,788 \\
\hline $\mathrm{CV}(\%)$ & - & 8,11 & 4,41 & 5,81 & 11,86 & 11,70 \\
\hline
\end{tabular}

$*$ = significativo a $5 \%$ de probabilidade.

ns $=$ não significativo a $5 \%$ de probabilidade.
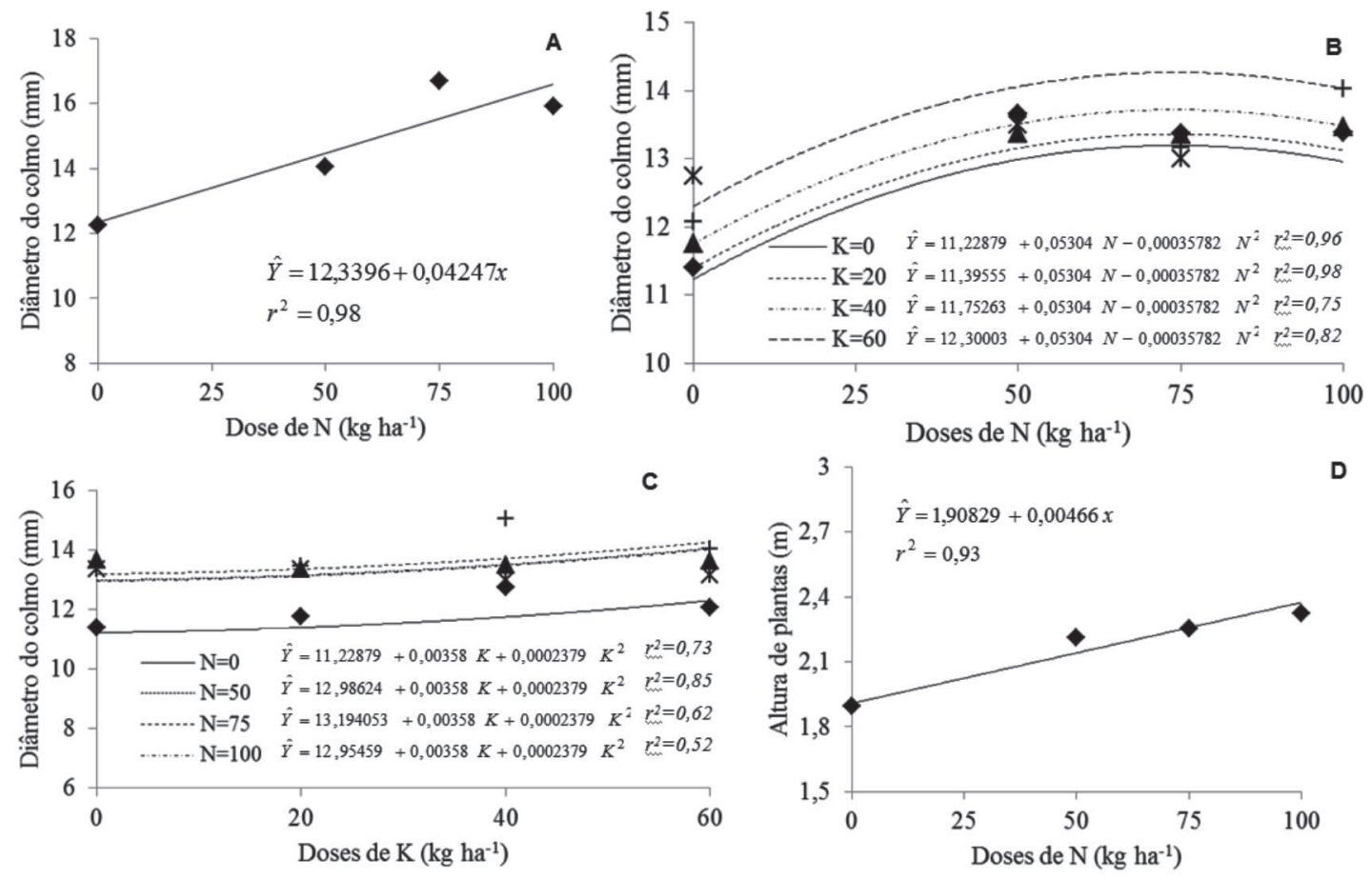

Figura 1. Respostas do minimilho submetido a diferentes doses de adubações nitrogenada e potássica. A: Diâmetro do colmo de plantas de minimilho em razão de doses de nitrogênio, safra verão. B: Diâmetro do colmo de plantas de minimilho em razão de doses de nitrogênio, safrinha. C: Diâmetro do colmo de plantas de minimilho em razão de doses de potássio, safrinha. D: Altura de plantas de minimilho em razão de doses de nitrogênio, safra verão. 
diretamente associada à produtividade, visto que tem o papel de disponibilizar fotoassimilados para o enchimento de grãos (Magalhães et al., 2001).

A altura de plantas de minimilho apresentou comportamento semelhante nas duas safras estudadas. Não houve efeito significativo $(\mathrm{P}>0,05)$ de $\mathrm{K}, \mathrm{K}^{2}$ e NK na altura de plantas na safra verão. Entretanto, ocorreu incremento linear na altura à medida que se aumentaram as doses de nitrogênio (Figuras 1D e 2A).

De acordo com Berry et al. (2003), a adubação nitrogenada tem ação sobre a elongação dos entrenós e, consequentemente, no acamamento. Com o incremento da disponibilidade de nitrogênio, as plantas apresentam maior crescimento vegetativo e aumento do comprimento dos entrenós. Esse fato aumenta o sombreamento mútuo entre as plantas, que recebem menor quantidade de radiação, modificando as propriedades biofísicas do colmo, resultando em menor resistência ao acamamento. A morfologia e a anatomia do colmo também são afetadas pelo nitrogênio e, por isso, são associadas ao acamamento. Dessa maneira, apesar da grande importância do nitrogênio na cultura do minimilho, sua utilização na adubação deve ser racional, pois além de aumentar o risco de acamamento pode causar prejuízos econômicos e poluição ambiental. Mesmo na dose mais elevada, a altura, na safra verão, manteve-se dentro do padrão considerado ótimo, ou seja, entre 1,9 e 2,5 m (Rodrigues et al., 2004; Embrapa, 2010).

Verificou-se também que não houve interação entre as doses de $\mathrm{N}$ e K no comprimento das espiguetas comerciais, ou seja, houve variação na referida variável somente com a adição de nitrogênio. Observou-se aumento linear no comprimento das espiguetas em razão do acréscimo de doses de nitrogênio tanto na safra verão (Figura 2B) como safrinha (Figura 2C).

Observa-se por meio das Figuras 2B e 2C, mesmo na maior dose de nitrogênio aplicada, que o comprimento de espiguetas considerado pelos consumidores como atributo de qualidade (Rodrigues et al., 2004) ficou de acordo com os padrões comerciais que exigem de 40 a $120 \mathrm{~mm}$ de comprimento. Segundo esse mesmo autor, tanto o comprimento de espiguetas como a altura de plantas são características menos afetadas pelas condições ambientais não controláveis. Isso explica o comportamento linear de ambas as variáveis nas duas safras analisadas. O comportamento das variáveis produtividade e número de espiguetas comerciais, em razão das doses crescentes de nitrogênio para a safra verão, está ilustrado nas Figuras 2D e 2E.

A produtividade de minimilho da safra verão não foi afetada pela aplicação de potássio (Tabela 2). Isso pode se justificar pelo alto teor disponível de K no solo. No entanto, houve incremento com as doses de nitrogênio (Figura 2D), sem apresentar interação significativa entre os fertilizantes potássico e nitrogenado. Observou-se comportamento quadrático para a referida variável em que a partir do ajuste do modelo de regressão foi possível estimar a resposta máxima de produtividade de $1.034,8 \mathrm{~kg}$ ha $^{-1}$ (máximo da função), a qual pode ser alcançada pela aplicação da dose de $64,35 \mathrm{~kg} \mathrm{ha}^{-1}$ (ponto de máximo) de nitrogênio. A dose associada ao melhor retorno econômico foi de $63,54 \mathrm{~kg} \mathrm{ha}^{-1}$.

Pavinato et al. (2008), em trabalho semelhante, porém avaliando a produtividade de grãos de milho sob irrigação por aspersão, observaram que a máxima eficiência econômica ocorre com a redução de $45 \%$ na dose de nitrogênio (em kg ha-1) quando comparada à máxima eficiência agronômica. Neste mesmo trabalho, observou-se que a aplicação de potássio não teve efeito sobre a produtividade, visto que os teores desse elemento no solo estavam em nível alto. Isso evidencia que, em muitas situações, os produtores utilizam fertilizantes nitrogenados e potássicos acima do recomendado.

Em trabalho realizado por Pereira Filho et al. (2002), os autores observaram que as produções total e comercial de minimilho, em diferentes cultivares de milho para produção de minimilho, não foram influenciadas por doses de nitrogênio aplicadas em cobertura (60 e $120 \mathrm{~kg} \mathrm{ha}^{-1}$ ).

Em contrapartida, muitos trabalhos demonstram que somente é possível aumentar a produtividade quando aplicadas altas doses de adubo nitrogenado. Rendimentos significativos de minimilho na Índia foram obtidos por Thakur \& Sharma (1999) com a dose de $200 \mathrm{~kg} \mathrm{ha}^{-1} \mathrm{de} \mathrm{N}$ aplicada em três parcelas iguais, sendo uma parte no plantio e as outras duas aos 25 e 40 dias após a semeadura. Segundo os autores, o aumento de $100 \mathrm{~kg} \mathrm{ha}^{-1}$ para $200 \mathrm{~kg}$ $\mathrm{ha}^{-1}$ de $\mathrm{N}$ promoveu acréscimo no rendimento de $10,26 \%$, e entre 100 e $150 \mathrm{~kg} \mathrm{ha}^{-1}$ não houve diferença significativa. Outros trabalhos conduzidos por Thakur et al. (1997) também mostraram acréscimos na produtividade com doses de nitrogênio acima de $100 \mathrm{~kg} \mathrm{ha}^{-1}$. Sahoo \& Panda (1999), trabalhando com doses de nitrogênio de 80,120 e $160 \mathrm{~kg}$ $\mathrm{ha}^{-1} \mathrm{e}$ três espaçamentos, verificaram maior rendimento na dose de $120 \mathrm{~kg} \mathrm{ha}^{-1}$ e na densidade 125.000 plantas por hectare. A produtividade de grãos e de matéria seca da parte aérea da planta de milho aumenta com a elevação das doses de nitrogênio (Araújo et al., 2004).

O tratamento de aplicação de nitrogênio permitiu o ajuste do modelo de regressão quadrática para a característica número de espiguetas comerciais, safra verão (Figura 2E). A partir do modelo de regressão ajustado foi possível estimar a resposta máxima do número de espiguetas comerciais em 158,6 espiguetas por parcela, o qual foi alcançado pela aplicação da dose de 57,92 $\mathrm{kg} \mathrm{ha}^{-1}$ de nitrogênio.

Os dados de número de espiguetas comerciais para o primeiro plantio tiveram comportamento semelhante ao dos resultados obtidos na avaliação da produtividade; ou seja, o maior rendimento pode ser justificado pelo aumento no 
número de espiguetas comerciais. A massa de espigas comerciais é considerada a característica mais importante para a produção de minimilho (Vasconcellos et al., 2001). O fornecimento combinado das doses de nitrogênio e potássio incrementou a produtividade do minimilho na safrinha (Figura 3A). A regressão polinomial indica que as doses necessárias de nitrogênio e potássio para a obtenção da máxima produtividade na safrinha, $977,29 \mathrm{~kg} \mathrm{ha}^{-1}$ foram de 60,90 e $51,23 \mathrm{~kg} \mathrm{ha}^{-1}$, respectivamente.

Doses altas de nitrogênio para o cultivo de minimilho, segundo Miles \& Zens (1997), não são necessárias, uma vez que se colhe o minimilho antes dos processos de crescimento e enchimento de grãos. Tais autores salientam que para o minimilho de 30 a $50 \mathrm{~kg} \mathrm{ha}^{-1}$ de nitrogênio mais o fósforo e potássio são suficientes para uma boa produção e que o nitrogênio mais o potássio não devem exceder $90 \mathrm{~kg} \mathrm{ha}^{-1}$ no sulco de plantio.
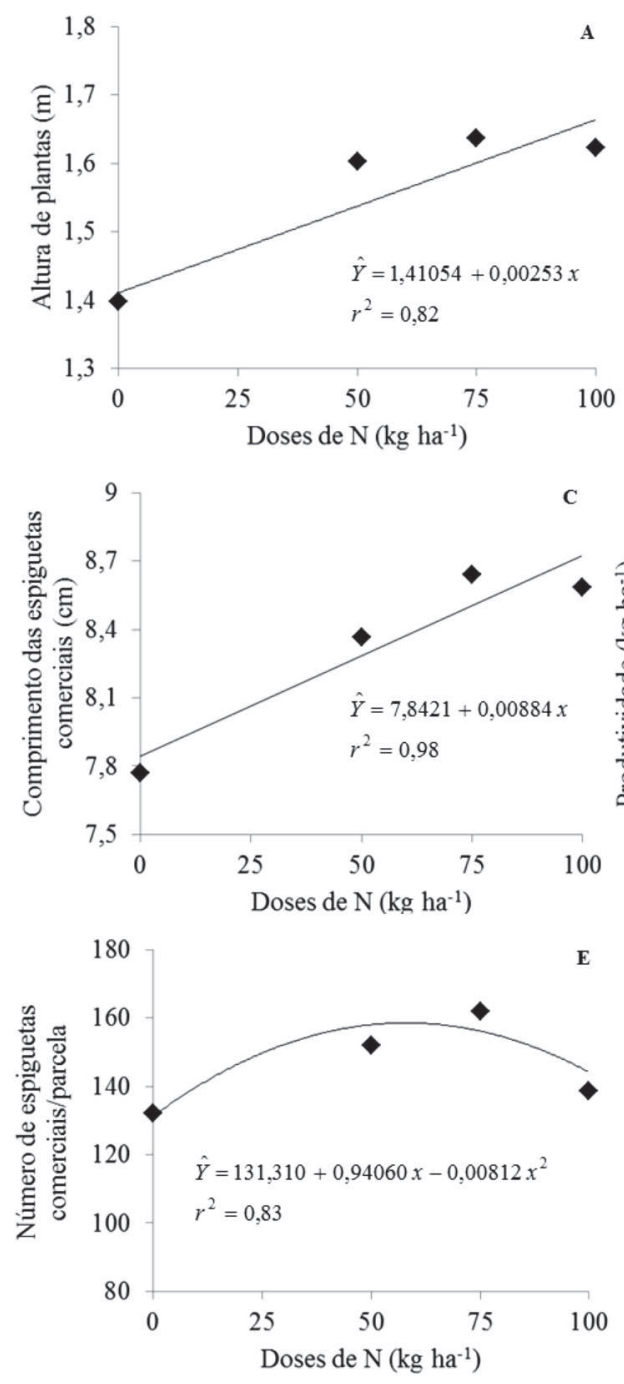

Figura 2. Respostas do minimilho submetido a diferentes doses de adubação nitrogenada. A: Altura de plantas de minimilho em razão de doses de nitrogênio, safrinha. B: Comprimento das espiguetas comerciais de minimilho em razão de doses de nitrogênio, Safra Verão. C: Comprimento das espiguetas comerciais de minimilho em razão de doses de nitrogênio, safrinha. D: Produtividade de minimilho em razão de doses de nitrogênio, safra verão. E: Número de espiguetas comerciais/parcela de minimilho em razão de doses de nitrogênio, safra verão.
Segundo Vasconcellos et al. (1998), próximo à fase de coleta das espiguetas o total de nitrogênio acumulado pelas plantas de milho pode alcançar $180 \mathrm{~kg} \mathrm{ha}^{-1}$, e desses apenas $22 \mathrm{~kg} \mathrm{ha}^{-1}$ serão exportados para as espiguetas. Para esses autores, apesar da grande retirada de nitrogênio, a exploração do minimilho, em razão do estádio da colheita, não responde a altas doses de nitrogênio. Em trabalho realizado com a cultura pelos mesmos autores, observou-se que o ganho obtido com a elevação da dose de $60 \mathrm{~kg} \mathrm{ha}^{-1}$ para $120 \mathrm{~kg} \mathrm{ha}^{-1}$ de $\mathrm{N}$ não compensou economicamente. Essas observações corroboram com os resultados obtidos no presente estudo, em que doses não tão elevadas permitiram o máximo retorno econômico.

Carvalho et al. (2003) verificaram produtividades de 730 a $1.200 \mathrm{~kg} \mathrm{ha}^{-1}$ com a aplicação de $152 \mathrm{~kg} \mathrm{ha}^{-1}$ de N e 64 $\mathrm{kg} \mathrm{ha}^{-1} \mathrm{de} \mathrm{K}$. Tais resultados comprovam que as maiores
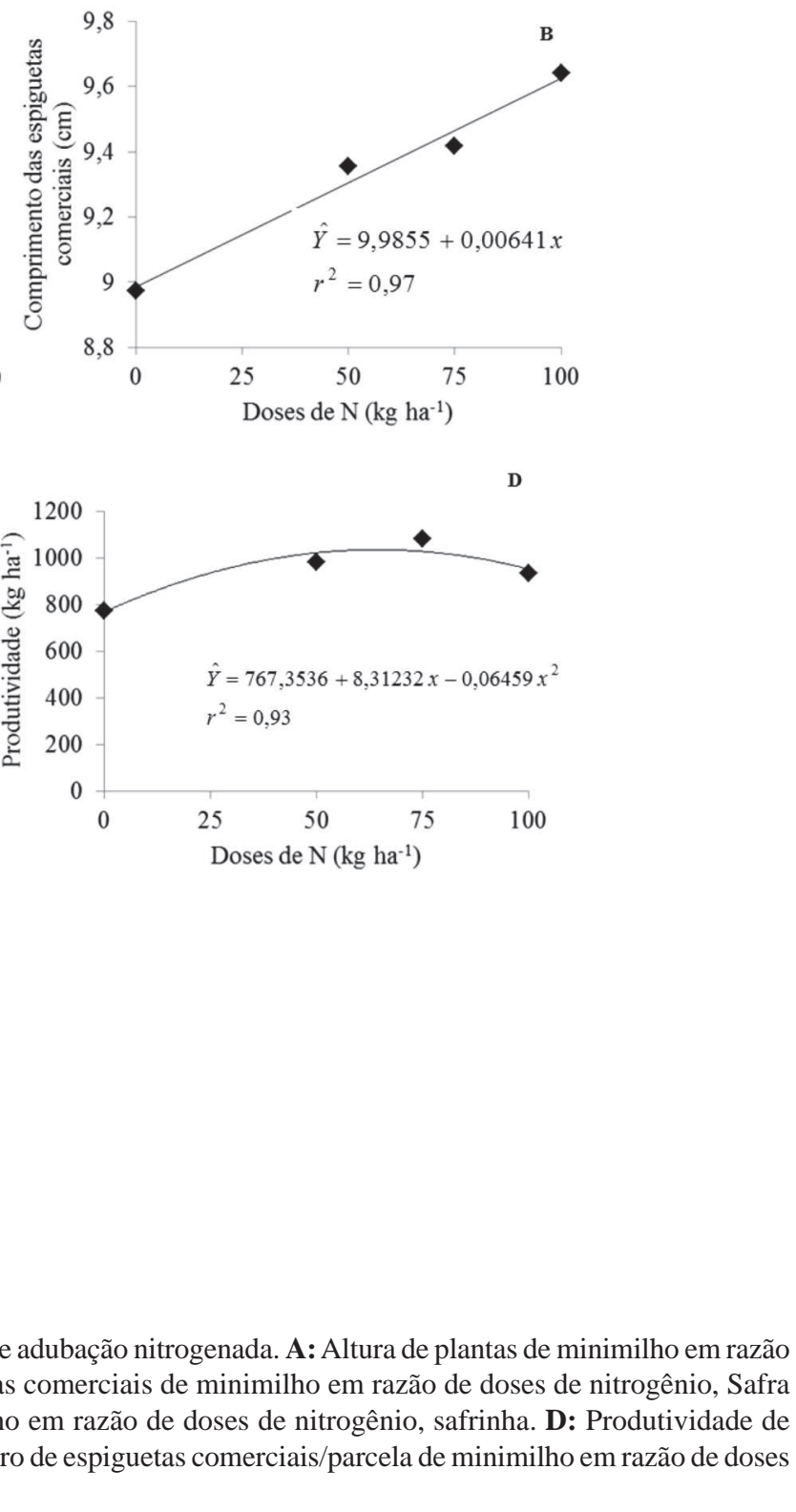

Rev. Ceres, Viçosa, v. 61, n.1, p. 121-129, jan/fev, 2014 


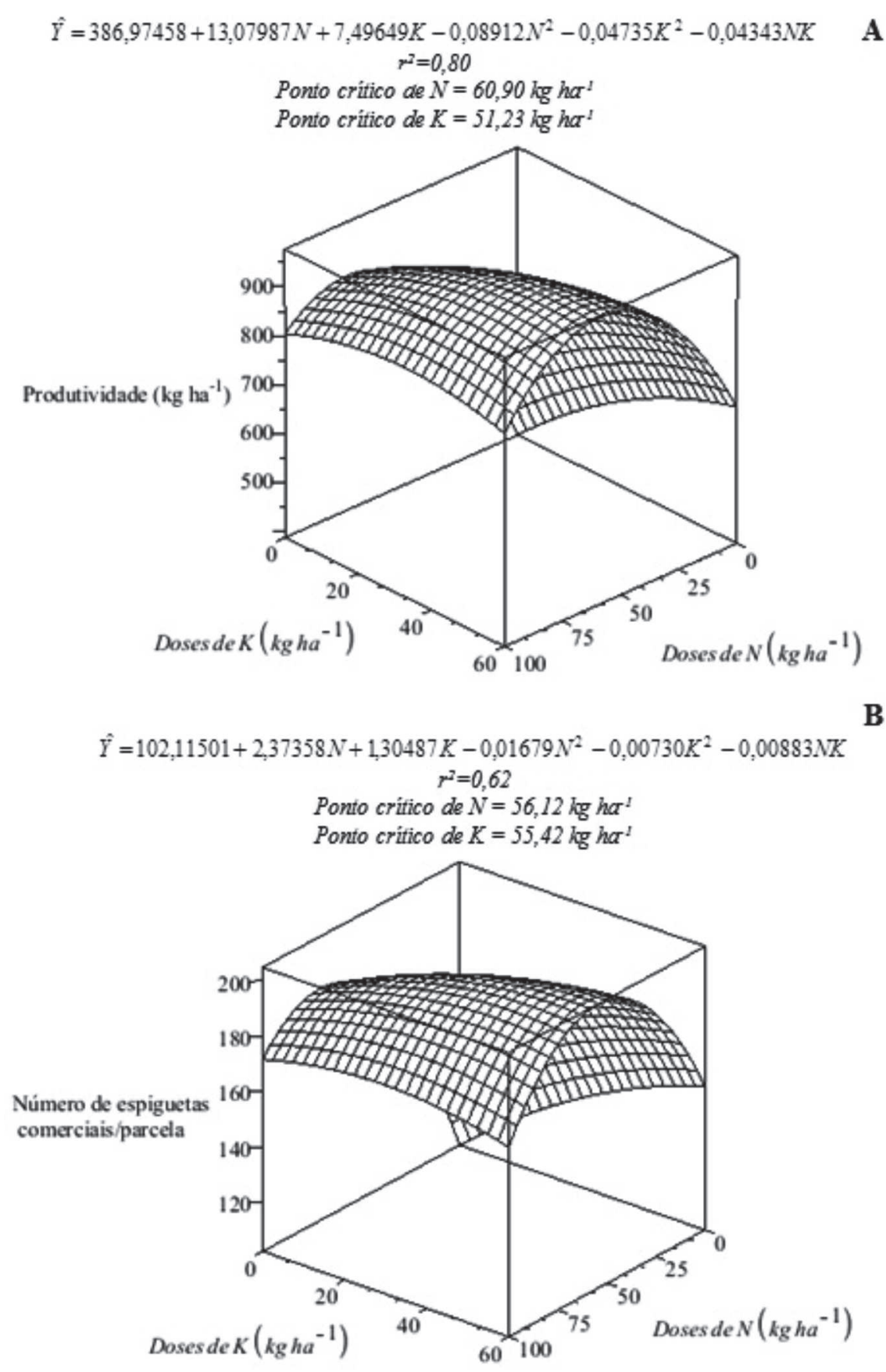

Figura 3. A: Produtividade de minimilho em razão das combinações de doses de nitrogênio e potássio, safrinha. B: Número de espiguetas comerciais/parcela em razão das combinações de doses de nitrogênio e potássio, safrinha.

doses de nitrogênio utilizadas nos estudos mencionados não resultaram em ganhos de produtividade; ou seja, a produtividade manteve-se próxima à que foi observada neste trabalho, porém com a utilização de doses menores dos nutrientes.

Comportamento semelhante ao da produtividade foi observado para a variável número de espiguetas comerciais de minimilho na safrinha (Figura 3B). Logo, o maior rendimento pode ser explicado pelo aumento no número de espiguetas comerciais. Essa característica é muito importante para a indústria de conserva (Rodrigues et al.,
2004). Os mesmos autores afirmam que, em conjunto com a produção de espigas, o número de espigas comerciais pode distinguir cultivares, ou variedade, mais adequados para o cultivo do minimilho e, portanto, é fator determinante em avaliações de rendimento.

A combinação das doses de nitrogênio e potássio permitiu o incremento na variável número de espiguetas. A aplicação de nitrogênio e potássio proporcionou ponto de máximo de 204,9 espiguetas comerciais por parcela nas doses de $56,12 \mathrm{~kg} \mathrm{ha}^{-1}$ de $\mathrm{N}$ e 55,42 $\mathrm{kg} \mathrm{ha}^{-1}$ de K. 


\section{CONCLUSÕES}

A máxima produtividade de minimilho na safra verão foi obtida com a aplicação de $64,35 \mathrm{~kg} \mathrm{ha}^{-1}$ de nitrogênio, não havendo incremento na produtividade com a aplicação de potássio, provavelmente em consequência da disponibilidade adequada desse nutriente no solo. Para o cultivo na safrinha, a maior produtividade foi observada com a combinação das doses 60,9 e $51,23 \mathrm{~kg} \mathrm{ha}^{-1}$ de nitrogênio e potássio, respectivamente.

\section{REFERÊNCIAS}

Almeida IPC, Silva PSL, Negreiros MZ \& Barbosa Z (2005) Baby corn, green ear and grain yield of corn cultivars. Horticultura Brasileira, 23:960-964.

Araújo LAN, Ferreira ME \& Cruz MCP (2004) Adubação nitrogenada na cultura do milho. Pesquisa Agropecuária Brasileira, 39:771-777.

Berry PM, Spink JH, Gay AP \& Craigon JA (2003) Comparison of root and stem lodging risks among winter wheat cultivars. Journal of Agricultural Science, 141:191-202.

Bull LT (1993) Nutrição mineral do milho. In: Bull LT \& Cantarella $\mathrm{H}$ (Eds.) Cultura do milho: Fatores que afetam a produtividade. Piracicaba, Potafós. p.63-145.

Carvalho GS, Von Pinho RG \& Rodrigues VN (2003) Produção de Minimilho em diferentes ambientes de Cultivo. Revista Ceres, 50:155-169.

Coelho AM (2006) Nutrição e Adubação de Milho. Sete Lagoas, Embrapa. 17p. (Circular Técnica, 78).

Embrapa - Empresa Brasileira de Pesquisa Agropecuária (1999) Sistema Brasileiro de Classificação de Solos. $1^{\text {a }}$ ed. Rio de Janeiro, Embrapa. 412p.

Embrapa - Empresa Brasileira de Pesquisa Agropecuária (2010) Minimilho: lucratividade dez vezes maior do que milho convencional. Disponível em: <http://www.portaldoagronegocio.com.br/ conteudo.php?id=37708>. Acessado em: 16 de dezembro 2011.

Epstein E (1975) Nutrição Mineral de Plantas: princípios e perspectivas. Rio de Janeiro, Editora Planta. 431p.

Fancelli AL \& Dourado-Neto D (2007) Milho: Fatores Determinantes da Produtividade. Piracicaba, ESALQ/USP/LPV. 219 p.

Luecking MA, Johnson JW \& Himes FE (1983) Effects of increasing the rates of potassium and nitrapyrin on nutrient uptake by corn. Agronomy Journal, 75:247-249.

Mackenzie AF, Phillip EE \& Kirby PC (1988) Effects of added urea and potassium chloride on yields of corn over four years and on soil potassium. Agronomy Journal, 80:773-777.

Magalhães PC, Oliveira E, Gomide RL, Vasconcellos CA \& Souza IRP (2001) Aspectos fisiológicos de plantas de milho infectadas por molicutes sob diferentes níveis de água no solo. Revista Brasileira de Fisiologia Vegetal, 13:293-301.

Miles CA \& Zens L (1997) Baby Corn Production. Chehalis, Washington State University Cooperative Extension. Disponível em: http://agsyst.wsu.edu/babycorn.htm. Acessado em: 5 de março de 2011.

Malavolta E (2006) Manual de nutrição mineral de plantas. Piracicaba, Editora Agronômica Ceres. 631p.

Marschner H (1995) Mineral nutrition of higher plants. London, Academic Press. 889p.
Pavinato PS, Ceretta CA, Girotto E \& Moreira ICL (2008) Nitrogênio e potássio em milho irrigado: análise técnica e econômica da fertilização. Ciência Rural, 38:358-364.

Pereira Filho IA, Gama EEG \& Cruz JC (1998) Minimilho: efeito de densidade de plantio e cultivares na produção e em algumas características da planta do milho. Sete Lagoas, EmbrapaCNPMS. 6p. (Comunicado Técnico, 23).

Pereira Filho IA \& Cruz JC (2000) Plantio, espaçamento, densidade, quantidade de sementes. In: Cruz JC, Versiani RP \& Ferreira MTR (Eds.) Cultivo do milho. Sete Lagoas, Embrapa Milho e Sorgo. Disponível em: <http://sistemasdeproducao.cnptia.embrapa.br/ FontesHTML/Milho/CultivodoMilho/plantio.htm>. Acessado em: 20 de novembro de 2011.

Pereira Filho IA \& Cruz JC (2001) Manejo Cultural do Minimilho. Sete Lagoas, Embrapa. 4p. (Circular Técnica, 07).

Pereira Filho IA, Vasconcellos CA, Cruz JC, Gama EEG \& Coelho AM (2002) Manejo da Adubação em Diferentes Cultivares de Milho para produção comercial de minimilho. In: XXIV Congresso Nacional de Milho e Sorgo: Meio Ambiente e a nova agenda para o agronegócio de milho e sorgo, Sete Lagoas. Anais, ABMS/ Embrapa Milho e Sorgo. p. 13-17.

Pereira Filho IA, Cruz JC \& Alvarenga RC (2005) Efeito de densidade de semeadura, níveis de nitrogênio e despendoamento sobre a produção de minimilho. Sete Lagoas, Embrapa Milho e Sorgo. 4p. (Comunicado técnico, 119).

Queiroz VAV (2008) Brasil não precisa mais importar minimilho. Disponível em: <http://www.parana-online.com.br/editoria/ almanaque/news/286684/>. Acessado em: 16 de novembro de 2011.

Ritchie SW, Hanway JJ \& Benson GO (2003) Como a planta de milho se desenvolve. Arquivo do Agrônomo Potafós, 103:01-20.

Rodrigues LR, Silva FN da \& Mori ES (2004) Avaliação de sete famílias S2 prolíficas de minimilho para a produção de híbridos. Bragantia, 63:31-38.

SAS Institute Inc. (2000) Statistical Analysis System user's guide. Version 8.0. Cary, Statistical Analysis System Institute. 513p.

Sahoo SC \& Panda MM (1999) Effect of level of nitrogen and plant population on yield of babycorn (Zea mays). Indian Journal Agricultural Sciences, 69:157-158.

Soratto RP, Pereira M, Costa TAM \& Lampert VN (2010) Fontes alternativas e doses de nitrogênio no milho safrinha em sucessão à soja. Revista Ciência Agronômica, Ceará, 41:511-518.

Souza EFC \& Soratto RP (2006) Efeito de fontes e doses de nitrogênio em cobertura, no milho safrinha, em plantio direto. Revista Brasileira de Milho e Sorgo, 5:395-405.

Thakur DR \& Sharma V (1999) Effect of varyang rates of nitrogen and its schedule of split application in babycorn (Zea mays). Indian Journal of Agriculture Sciences, 69:93-95.

Thakur DR, Prakash O, Kharwara PC \& Bhalla SK (1997) Effect of nitrogen and plant spacing on growth, yield and economics of babycorn (Zea mays). Indian Journal of Agronomy, 42:179-183.

Vasconcellos CA, Viana MCM \& Ferreira JJ (1998) Acúmulo de matéria seca e de nutrientes em milho cultivado no período inverno-primavera. Pesquisa Agropecuária Brasileira, 33:18351845 .

Vasconcellos CA, Alves VMC, Pereira Filho IA \& Pitta GVE (2001) Nutrição e adubação do milho visando a obtenção do minimilho. Sete Lagoas, Embrapa. 10p. (Comunicado Técnico, 09).

Xu QF, Tsai CE \& Tsai CY (1992) Interaction of potassium with the form and amount of nitrogen nutrition on growth and nitrogen uptake of maize. Journal of Plant Nutrition, 15:23-33.

Rev. Ceres, Viçosa, v. 61, n.1, p. 121-129, jan/fev, 2014 